\title{
PERAN TEKNOLOGI INFORMASI DALAM PENYULUHAN PETERNAKAN DI DESA KANONANG KECAMATAN KAWANGKOAN BARAT KABUPATEN MINAHASA
}

\author{
Inka M. N. Ruru, G. D. Lenzun*, S. O. B. Lombogia
}

\section{Fakultas Peternakan Universitas Sam Ratulangi Manado, 95115}

\begin{abstract}
ABSTRAK
Teknologi informasi setiap tahun menunjukan kemajuan yang sangat dahsyat, sebagai bukti contoh kecil, gadget yang sudah tidak asing lagi di telinga kita yaitu telepon seluler

informasi dalam penyuluhan peternakan di Desa Kanonang, Kecamatan Kawangkoan Barat, Kabupaten Minahasa tidak berperan, karena kuatnya adat tradisional secara turun temurun dari peternak.
\end{abstract} atau handphone dan computer. Perkembangan zaman yang semakin modern menciptakan berbagai macam teknologi yang semakin canggih sehingga membuat hampir tidak ada bidang kehidupan manusia yang bebas dari penggunaannya khususnya teknologi komunikasi yang saat ini mampu memberikan transformasi bagi kehidupan manusia. Smartphone dapat digunakan sebagai sarana pembelajaran, dimana melalui smartphone seseorang dapat mempelajari hal-hal baru melalui isi atau pesan yang disalurkan. Penelitian ini bertujuan untuk mengetahui bagaimana peran teknologi informasi terhadap peternak di Desa Kanonang, Kecamatan Kawangkoan Barat, Kabupaten Minahasa. Sumber data yaitu primer dan sekunder. Metode pengumpulan data observasi dan wawancara. Populasi penelitian 54 peternak dan jumlah sampel di ambil 36 peternak. Penentuan sampel secara purposive sampling yaitu Desa Kanonang, Kecamatan Kawangkoan Barat, Kabupaten Minahasa indikator penelitian dengan skala likert. Analisis yang digunakan yaitu Chi Square. Berdasarkan hasil penelitian, maka dapat disimpulkan, bahwa teknologi

Korespondensi (corresonding author) Email: saguer64@yahoo.com
Kata kunci: Peran, teknologi informasi, Desa Kanonang.

\section{ABSTRACT}

THE ROLE OF TECHNOLOGICAL INFORMATION IN ANIMAL FARM EXTENSION AT KANONANG VILLAGE, WEST KAWANGKOAN DISTRICT OF MINAHASA REGENCY. The technological information was developing annually, indicated by gadget tool combined by the computer tools. All aspects of human need were using technological information. The smart-phone can be used as tools of study processing to deliver knowledge massages. Objective of this study was to evaluate the role of technological information in the animal farm extension at Kanonang village, district of West Kawangkoan in Minahasa regency. Data were collected from primary and secondary sources. The direct observation and discussion were applied to obtain primary data. Total of 36 sample farmers defined by purposive sampling were taken from 54 household farmers at Kanonang village. Indicator of study was using likert scale. Data were analyzed by Chi square method. Result showed that the technological 
information did not play the role in animal farm extension at Kanonang village due to strong traditional system of the community occurring from the previous generation to the next recently generation.

Keywords: Information technology, animal farm extension, Kanonang village.

\section{PENDAHULUAN}

Kemajuan teknologi adalah sesuatu yang tidak bisa dihindari dalam kehidupan ini, karena kemajuan teknologi akan berjalan sesuai dengan kemajuan ilmu pengetahuan (Ngafifi, 2014). Perkembangan teknologi informasi dari tahun ke tahun sudah menunjukan kemajuan yang sangat baik (Supriyanto, 2005). Menurut Munir (2009), pada zaman sekarang ini handphone tidak hanya sebagai alat komunikasi saja tetapi lebih dari itu sudah berfungsi sebagai radio, televisi, kamera dan layanan internet lainnya.. Teknologi informasi adalah teknologi yang menggabungkan komputasi (komputer) dengan jalur komunikasi kecepatan tinggi yang membawa data, suara, dan video (Kadir, 2003). Teknologi Informasi memang menyajikan dan menjanjikan kecepatan, yang merupakan salah satu faktor yang sangat dituntut dalam pengelolaan informasi (Zuhrah, 2011). Penggunaan teknologi informasi memiliki keuntungan yaitu kecepatan, konsistensi, ketepatan dan keandalan (Sutarman, 2009). Perkembangan teknologi handphone pun sangat pesat. Teknologi informasi membuat peneliti tertarik melaksanakan penelitian untuk melihat peran teknologi komunikasi saat ini. Kondisi ini berkaitan pula dengan banyaknya tuntutan kebutuhan akan pertukaran informasi yang cepat dan tepat (Saleh, 2016). Dalam pengaplikasiannya, smartphone berguna dan sangat membantu peternak khususnya ketika berada pada usaha peternakan dan dalam kegiatan pemeliharaannya, tetapi belum tentu semua yang diakses oleh smartphone adalah hal-hal baik yang dapat menunjang usaha dan pemeliharaan ternak (Prawiranegara, 2016). Dalam UU No. 11 Tahun 2008 tentang Informasi dan Transaksi Elektrik mengatur kepada semua pengguna Teknologi Informasi untuk dapat memberi informasi dan menggunakan dengan baik menurut aturan dan bukan dengan memberikan berita bohong (Pradjonggo, 2013). Dilihat dari perkembangan masalah saat ini, penulis tertarik untuk mengetahui peran dari teknologi informasi berupa smartphone 
dan komputer dari peternak dalam menunjang usaha peternakan karena dari pengamatan di lapangan bahwa sudah banyak peternak memiliki handphone yang berbasis smartphone dan komputer (Supriyadi dan Kiswanto, 2010). Penyuluhan adalah usaha memberikan keterangan, penjelasan, petunjuk, bimbingan, tuntunan, jalan dan arah yang harus ditempuh oleh setiap orang sehingga dapat memecahkan masalah yang dihadapinya dan meningkatkan kualitas hidupnya (Janis, 2014). Penyuluhan adalah ilmu yang mempelajari perilaku manusia ke arah yang lebih baik, perilaku manusia dapat berubah atau diubah sehingga mau meninggalkan kebiasaan lama dan menggantikannya dengan perilaku baru yang berakibat kualitas kehidupan orang yang bersangkutan menjadi lebih baik (Narso et al., 2012). Masyarakat di Desa Kanonang Kecamatan Kawangkoan Barat sudah menggunakan handphone sebagai sarana komunikasi namun bagaimana perannya terhadap penyuluhan peternakan di wilayah ini menarik untuk di kaji. Karena itu perlu dilakukan penelitian begaimana peran teknologi informasi terhadap penyuluhan peternakan di Desa Kanonang Kecamatan Kawangkona.

\section{METODE PENELITIAN}

Penelitian ini dilaksanakan di Desa Kanonang Kecamatan Kawangkoan Barat pada bulan April 2019. Penelitian ini berbentuk survey menggunakan kuesioner sebagai instrumen utama. Berbagai sumber data yang akan dimanfaatkan dalam penelitian ini sebagai berikut. Data primer adalah data dalam bentuk verbal atau kata-kata yang diucapkan secara lisan, gerak-gerik, atau perilaku yang dilakukan oleh subjek yang dapat dipercaya, dalam hal ini adalah subjek penelitian (informan) yang berkenan dengan variable yang diteliti. Data sekunder dalam penelitian ini adalah data yang diperoleh dari dokumendokumen, foto-foto, benda-benda, dan lain-lain yang di dapat dari instansi pemerintah. Teknik pengumpulan data yang digunakan dalam penelitian ini adalah kuesioner yakni berupa daftar pertanyaan yang berkaitan dengan masalah penelitian yang harus dijawab dan diisi oleh responden sebagai sampel yang dipilih. Responden dalam penelitian ini ialah peternak yang sudah menggunakan teknologi informasi berupa smartphone dan komputer. Populasi dalam penelitian ini yaitu peternak yang ada di Desa Kanonang 
Kecamatan Kawangkoan Barat

Kabupaten Minahasa. Sampel penelitian ialah desa yang memiliki peternak dan juga yang sudah menggunakan teknologi informasi berupa komputer dan telepon genggam (handphone) yang bisa menggunakan akses internet. Jumlah populasi peternak di desa kanonang ini adalah 54 orang peternak dengan jumlah sampel yang di ambil yaitu 36 orang peternak. Penetapan jumlah sampel dilakukan menggunakan rumus Slovin dengan tingkat kesalahan 10\% (Sevilla, 2007).

$$
\begin{aligned}
& \mathbf{n}=\mathbf{N} /\left(\mathbf{1}+\left(\mathbf{N} \times \mathbf{e}^{2}\right)\right. \\
& n=54 /\left(1+\left(54 \times 0,1^{2}\right)\right. \\
& n=54 /(1+(54 \times 0,01) \\
& n=54 /(1+0,54) \\
& n=54 / 1,54 \\
& n=35,06
\end{aligned}
$$

Hubungan antara variabel-variabel dalam peran teknologi informasi yang meliputi variable peternak dengan sikap dan perilaku dalam keberhasilan pengembangan usaha peternakan dengan masing-masing diuji menggunakan uji Kai Kuadrat.(Chi square)

Sebagai rumus dasar dari uji Kai Kuadrat adalah:

$$
\chi^{2}=\frac{o i-e i^{2}}{e i}
$$

Keterangan :

$\chi^{2}=$ Chi Square

$\mathrm{o} i=$ Frekuensi hasil observasi

$e i \quad=$ Frekuensi yang diharapkan

\section{HASIL DAN PEMBAHASAN}

Smartphone yaitu telepon selular dengan mikroprosesor, memori, layar dan modem bawaan (Budiman, 2017). Smartphone merupakan ponsel multimedia yang menggabungkan fungsionalitas PC dan handset sehingga menghasilkan gadget yang mewah.

Tabel 1 menunjukkan bahwa responden hanya menggunakan smartphone sebagai alat komunikasi dan tidak ada yang menggunakan komputer.

Elian et al. (2014) menemukan bahwa penggunaan internet masih tergolong rendah.

Hasil penelitian pada Tabel 2 dibawah menunjukkan bahwa sebanyak $55,56 \%$ responden tidak setuju dengan penggunaan teknologi informasi dalam usaha peternakan dan sebanyak $44,44 \%$ responden setuju dengan penggunaan teknologi informasi dalam usaha peternakan. 
Tabel 1. Pemilikan Smartphone Dan Komputer

\begin{tabular}{ccccc}
\hline & & \multicolumn{2}{c}{ Jumlah (orang) } & Total \\
\cline { 3 - 4 } No & Alat Komunikasi & Ya & Tidak & \\
\cline { 3 - 4 } & Smartphone & 22 & 14 & $\mathbf{3 6}$ \\
\hline 1. & Komputer & 0 & 36 & $\mathbf{3 6}$ \\
\hline
\end{tabular}

Tabel 2. Penggunaan Teknologi Informasi Dalam Usaha Peternakan

\begin{tabular}{cccc}
\hline No & $\begin{array}{c}\text { Penggunaan Teknologi Informasi } \\
\text { (S/TS) }\end{array}$ & $\begin{array}{c}\text { Jumlah } \\
\text { (orang) }\end{array}$ & Persentase (\%) \\
\hline 1 & Setuju & 16 & 44,44 \\
2 & Tidak Setuju & 20 & 55,56 \\
\hline & Total & 36 & 100 \\
\hline
\end{tabular}

Tabel 3. Peran Teknologi Informasi Untuk Peternak

\begin{tabular}{cccc}
\hline Variabel & Kategori & $\begin{array}{c}\text { Jumlah } \\
(\text { Orang) }\end{array}$ & $\begin{array}{c}\text { Persentase } \\
(\%)\end{array}$ \\
\hline \multirow{3}{*}{ Peran Teknologi Informasi } & Berperan & 16 & 44,44 \\
& Tidak Berperan & 20 & 55,56 \\
\hline & & 36 & 100 \\
\hline
\end{tabular}

Tabel 4. Analisis Tabel Kontingensi

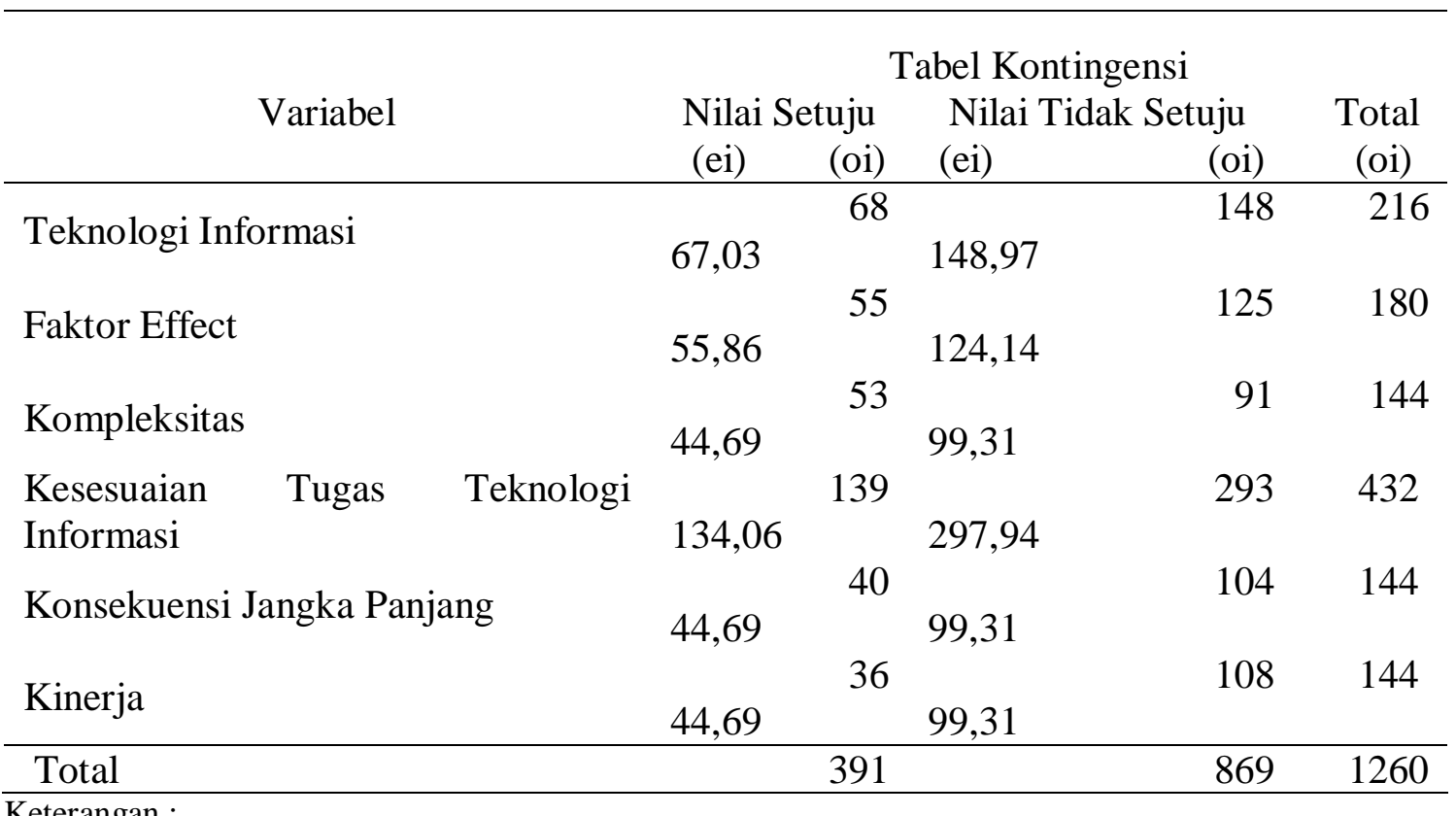

Keterangan :

ei $=$ Nilai yang diharapkan. $\quad$ oi $=$ Nilai pengamatan dilapangan atau nilai nyata. 
Tabel 5. Uji Analisis Chi Square Peran Teknologi Informasi Dalam Penyuluhan Peternakan

\begin{tabular}{lccccc}
\hline \multicolumn{1}{c}{ Kategori } & oi & ei & (oi-ei) & $($ oi-ei) & (oi-ei) $)^{2} / \mathrm{ei}$ \\
\hline Teknologi Informasi (oi) & 68 & 67,03 & 0,97 & 0,9409 & 0,014036998 \\
Faktor Effect (oi) & 55 & 55,86 & $-0,86$ & 0,7396 & 0,013240244 \\
Kompleksitas (oi) & 53 & 44,69 & 8,31 & 69,0561 & 1,545224883 \\
Kesesuaian Tugas (oi) & 139 & 134,06 & 4,94 & 24,4036 & 0,18203491 \\
Konsekuensi Jangka Panjang (oi) & 40 & 44,69 & $-4,69$ & 21,9961 & 0,492192884 \\
Kinerja (oi) & 36 & 44,69 & $-8,69$ & 75,5161 & 1,689776236 \\
Teknologi Informasi (ei) & 148 & 148,97 & $-0,97$ & 0,9409 & 0,006316037 \\
Faktor Effect (ei) & 125 & 124,14 & 0,86 & 0,7396 & 0,00595779 \\
Kompleksitas (ei) & 91 & 99,31 & $-8,31$ & 69,0561 & 0,6953589769 \\
Kesesuaian Tugas (ei) & 293 & 297,94 & $-4,94$ & 24,4036 & 0,081907767 \\
Konsekuensi Jangka Panjang (ei) & 104 & 99,31 & 4,69 & 21,9961 & 0,221489276 \\
Kinerja (ei) & 108 & 99,31 & 8,69 & 75,5161 & 0,760407814 \\
\hline Jumlah & 1260 & 1260 & & & 4,791095562 \\
\hline
\end{tabular}

Berdasarkan Tabel 3,

sebanyak 20 responden mengatakan bahwa dalam usaha peternakan teknologi informasi tidak berperan dan sebanyak 16 responden mengatakan teknologi informasi berperan dalam penyuluhan peternakan. Hal ini menunjukkan bahwa masyarakat di Desxa Kanonang pada umumnya masih mengelola peternakan secara tradisional dibandingkan dengan peternakan modern yang sudah menggunakan teknologi informasi. Penelitian sejalan dengan Sapari, (2009) bahwa masyarakat tradisional umumnya belum menggunakan teknologi informasi sebagai sarana uintuk mengembangkan usaha pertaniannya.

Untuk mengetahui berperan atau tidak berperannya teknologi informasi di Desa Kanonang Kecamatan Kawangkoan Barat 
maka dilakukan pengujian variable dengan teknik chi square padfa taraf uji 5\%. Ukuran Tabel kontingensi padfa Tabel 4 di atas $=$ adalah $6 \times 2(6$ baris dan 2 kolom) doimana $\mathrm{db}=(6-$ 1)(2-1) $=5 \times 1=5$. Nilai Tabel $\chi^{2}$ pada $\mathrm{db}=5 ; a=0.05$ adalah 16,750 sedangkan nilai $\chi^{2}$ hitung sebesar $4,791095562<\chi^{2}$ tabel 16,750.

Karena itu hasil analisis pada Tabel 5 menunjukkan bahwa $\mathrm{H}_{0}$ diterima yaitu teknologi informasi tidak berperan dalam penyuluhan peternakan di Desa Kanonang Kecamatan Kawangkoan Barat Kabupaten Minahasa.

Hal ini menunjukkan bahwa teknologi informasi dalam penyuluhan peternakan tidak berhasil karena kuatnya adat tradisional di daerah penelitian.

\section{KESIMPULAN}

Berdasarkan hasil penelitian, maka dapat disimpulkan bahwa, Teknologi Informasi di Desa Kanonang Kecamatan Kawangkoan Barat Kabupaten Minahasa tidak berperan dalam penyuluhan peternakan karena kuatnya adat tradisional peternak secara turun temurun.

\section{DAFTAR PUSTAKA}

Budiman, H. 2017. Peran teknologi informasi dan komunikasi dalam pendidikan. Jurnal Pendidikan Islam 8(1):1-12

Elian, N., D.P. Lubis dan P.A. Rangkuti. 2014. Penggunaan internet dan pemanfaatan informasi pertanian oleh penyuluh pertanian di Kabupaten Bogor wilayah Barat. Jurnal Komunikasi Pembangunan 12(2):104-109

Janis, R.L. 2014. Kinerja penyuluhan pertanian di wilayah kerja Badan Pelaksana Penyuluhan Pertanian Perikanan dan Kehutanan (BP4K) Kabupaten Kepulauan Sangihe. Jurnal Cocos 4(4):20-41

Kadir, A. 2003. Pengenalan Sistem Informasi. Andi. Yogyakarta.

Pradjonggo, T.S. 2013. Efektifitas undang-undang nomor 11 tahun 2008 tentang informasi dan transaksi elektronik terhadap maraknya pelanggaran hukum pidana pada media sosial. Journal Article Likhitaprajna 15(1):61

Munir. 2009. Kontribusi Teknologi Informasi dan Komunikasi (TIK) dalam pendidikan di era globalisasi pendidikan Indonesia. Jurnal Pendidikan Teknologi Informasi dan Komunikasi 2(2):1-4

Narso, A.S., P.S. Asngari dan P. Muljono. 2012. Persepsi penyuluh pertanian lapang tentang perannya dalam 
penyuluhan pertanian padi di Provinsi Banten. Jurnal Penyuluhan 8(1):92-102

Ngafifi, M. 2014. Kemajuan teknologi dan pola hidup manusia dalam perspektif sosial budaya. Jurnal Pembangunan Pendidikan: Fondasi dan Aplikasi 1(1):33-47

Prawiranegara, D. 2016. Pengaruh kualitas informasi berbasis cyber terhadap kapabilitas petani sayuran mengelola inovasi di Jawa Barat. Jurnal Sosiohumaniora 18(2):166172

Saleh. A. 2016. Tingkat penggunaan media massa dan peran komunikasi anggota kelompok peternak dalam jaringan komunikasi penyuluh sapi potong. Jurnal Media Peternakan 29(2):108

Sapari, Y. 2009. Pemanfaatan media komunikasi prima tani, aksebilitas kelembagaan tani dan persepsi petani tentang teknologi agribisnis industrial pedesaan. Jurnal Komunikasi Pembangunan 7(1): 1-12.

Sevilla, C. 2007. Research Methods. Rex Printing Company. Quezon City

Supriyanto, A. 2005. Pengantar Teknologi Informasi. Salemba Empat. Jakarta

Sutarman. 2009. Pengantar Teknologi Informasi. Bumi Aksara. Jakarta
Supriyadi, E. dan M.H. Kiswanto. 2010. Teknologi informasi dan komunikasi. CV Sinar Mandiri. Jakarta.

Zuhrah, S. 2011. Pentingnya teknologi informasi dalam meningkatkan pelayanan di perpustakaan. Jurnal Iqra 5(1):40-49 